\title{
From antagonism to synergism: Extreme differences in stressor interactions in one species
}

\author{
Lars Straub $b^{1,2,3^{*}}$, Angela Minnameyer ${ }^{1,3^{*}}$, Verena Strob| ${ }^{1}$, Eleonora Kolari ${ }^{1}$, Andrea Friedli ${ }^{1}$, \\ Isabelle Kalbermatten ${ }^{1}$, Antoine Joseph Willem Marie Merkelbach ${ }^{1}$, Orlando VictorYañez ${ }^{1}$ \& \\ Peter Neumann ${ }^{1,2}$
}

Interactions between stressors are involved in the decline of wild species and losses of managed ones. Those interactions are often assumed to be synergistic, and per se of the same nature, even though susceptibility can vary within a single species. However, empirical measures of interaction effects across levels of susceptibility remain scarce. Here, we show clear evidence for extreme differences in stressor interactions ranging from antagonism to synergism within honeybees, Apis mellifera. While female honeybee workers exposed to both malnutrition and the pathogen Nosema ceranae showed synergistic interactions and increased stress, male drones showed antagonistic interactions and decreased stress. Most likely sex and division of labour in the social insects underlie these findings. It appears inevitable to empirically test the actual nature of stressor interactions across a range of susceptibility factors within a single species, before drawing general conclusions.

In light of the recent reported high losses of biodiversity within the past centuries ${ }^{1,2}$, it is apparent that the Earth is undergoing its sixth mass extinction event ${ }^{3,4}$. While the often charismatic megafauna has long been the focus, insects have only recently received attention ${ }^{5}$, despite their indispensable role for both functionalities of terrestrial ecosystems and human food security ${ }^{6,7}$. Indeed, mounting evidence revealing both global declines in insect biomass as well as the diversity of insect pollinators has raised great concern ${ }^{8-10}$. A wide array of drivers are held responsible for the reported declines, including global climate change, habitat loss, intensified agricultural practices as well as the spread of pests and pathogens ${ }^{11-13}$.

Naturally, these stress factors act upon our environment simultaneously ${ }^{14}$, causing complex interactions that may mitigate or exacerbate effects on an individual species or population ${ }^{15}$. The potential negative consequences of such interactions upon wild insect populations have been shown in both North America and Britain, where intensified agriculture in combination with the loss of nutritional resources or diseases caused severe declines in pollinator species ${ }^{16,17}$. Subsequently, there is a general consensus that the interactions of combined stressors are a highly plausible explanation for recent species extinctions and population declines. However, a vast knowledge gap remains in understanding how susceptibility may vary amongst species facing combined stressor scenarios.

Inter- and intra-specific species variability in stressor sensitivity is known ${ }^{18}$. For instance, biotic homogenization is likely to impose larger consequences on specialist insects compared to generalists ${ }^{13}$. Thus, extrapolating stressor effects from one species to another without considering fundamental differences in life-history traits or phenology may not be appropriate ${ }^{19}$. Furthermore, within a species, differences in age groups ${ }^{20}$, developmental stage $^{21}$ and $\operatorname{sex}^{22,23}$ may play a crucial role in understanding susceptibility. This is further underlined by the importance of considering varying genetics as a key factor ${ }^{24}$. Moreover, in various insect orders (Hymenoptera, Thysanoptera, and Coleoptera), the haplo-diploid sex determination system, where females are diploid and males usually develop from unfertilized eggs and are haploid, reveals an additional level of intricacy ${ }^{25}$. This becomes evident when considering the haploid-susceptibility hypothesis, which postures that a lack of heterozygosity at immune loci may result in reduced immunocompetence ${ }^{26}$, yet empirical data remain scarce. Lastly, the possible influence of reproductive division of labour, one cornerstone of the biology of social insects ${ }^{27}$, remains relatively unexplored ${ }^{28}$, despite colony demographics and polyethism having been shown to influence disease susceptibility ${ }^{29}$.

${ }^{1}$ Institute of Bee Health, Vetsuisse Faculty, University of Bern, Bern, Switzerland. ${ }^{2}$ Agroscope, Swiss Bee Research Centre, Bern, Switzerland. ${ }^{3}$ These authors contributed equally: Lars Straub and Angela Minnameyer. *email: lars. straub@vetsuisse.unibe.ch; angela.minnameyer@vetsuisse.unibe.ch 
The eusocial western honeybee, Apis mellifera, has historically served as a model organism to investigate the effects of environmental and anthropogenic stressors, mainly due to its role as a managed pollinator species, as well as their comparatively well-studied biology $y^{30,31}$. By taking advantage of division of labour and complementary sex determination ${ }^{32}$ in the honeybees, we aim to test possible different levels of susceptibility in haploid male (drone) and diploid female (worker) bees towards two common honeybee stressors: an obligatory intracellular midgut parasite, Nosema ceranae, and malnutrition. Both N. ceranae and poor nutrition can compromise immunocompetence $e^{33,34}$ and individual bee physiology (e.g. reduced body mass ${ }^{35,36}$ ) which may ultimately explain increased mortality rates ${ }^{37}$. Considering previous studies and the expectations from the haploid-susceptibility hypothesis, we hypothesize that the combined treatments will not only reveal significant negative synergistic effects upon individuals, but that these effects will be amplified in the haploid drones.

\section{Results}

Consumption. No significant differences were found for sugar water consumption amongst treatment groups $\left(F_{3,270}=2.4, P>0.05\right.$; Electronic Supplementary Material ESM Figure S2A), with the average daily bee consumption ranging between $38.11 \pm 11.08 \mathrm{mg}$ and $40.72 \pm 8.62 \mathrm{mg}$ (mean \pm S.D.; ESM Table S3). Median pollen consumption for Controls $(2.08 \pm 0.34-6.24 \mathrm{mg})$ did not differ from Pathogen $(2.48 \pm 0.30-7.43 \mathrm{mg})\left(F_{1,136}=0.60\right.$; $P>0.05$; median 95\% C.I.; ESM Table S3). The average daily pollen consumption ranged between $1.85 \pm 1.61 \mathrm{mg}$ and $2.63 \pm 2.12 \mathrm{mg}$ (mean \pm S.D; ESM Table 2$)$. Pollen consumption significantly differed over the experimental period $\left(F_{5,125}=104.88 ; P<0.05 ;\right.$ ESM Figure S2B).

Survival. Drones. Median cumulative survival [\%] at day 14 for Malnutrition (76.1 \pm 70.6 - 81.6) and Combined (76.8 \pm 70.3 - 83.4) treatments did not significantly differ from Controls (75.2 \pm 69.9 - 80.6) (all $P s>0.483$, median $\pm 95 \%$ C.I.; Fig. 1A). In contrast, Pathogen (64.5 $\pm 58.2-70.6)$ had significantly lower survival when compared to Controls and the remaining treatments (all $P s<0.003$, median $\pm 95 \%$ C.I.; Fig. 1A), which resulted in a reduction in survival of $14 \%$. The Combined treatment lead to an antagonistic interaction and showed decreased stress when compared to their relative single stressor treatments (ESM Table S4).

Workers. No significant difference in median cumulative survival [\%] was observed between Controls $(74.6 \pm 70.8$ - 78.42) and Pathogen $(71.1 \pm 66.9$ - 75.37) $(P=0.102)$. In contrast, Malnutrition $(61.52 \pm 57.08-$ 65.97) and Combined (52.2 \pm 46.7 - 57.7) resulted in significant reductions of survival (all $P s<0.001$, median \pm $95 \%$ C.I., Fig. 1B), whereby survival was reduced by $18 \%$ and $30 \%$, respectively. The Combined treatment revealed a synergistic interaction and increased stress compared to the single stressors (ESM Table S4).

Body mass. Drones. All treatment groups revealed significant reductions in body mass (9\% - 16\%) 14 days post-emergence when compared to the Newly Emerged drones (261.2 \pm 23.6$)$ (all $P s<0.001 ;$ mean \pm S.D.; ESM Figure S3A). Pollen fed bees from the Pathogen treatment $(235.6 \pm 25.3 \mathrm{mg})$ did not significantly differ from the Controls $(239.0 \pm 24.0 \mathrm{mg})(P=1.00$; mean $\pm \mathrm{SD}$; ESM Figure S3A). In contrast, treatment groups without pollen showed significantly reduced body mass compared to Controls (all $P s<0.001$, ESM Figure S3A). This translated to a reduction in body mass for the Malnutrition $(218.5 \pm 24.24 \mathrm{mg})$ and Combined $(220.7 \pm 19.9 \mathrm{mg})$ of $8.6 \%$, and $7.6 \%$, respectively (mean $\pm 95 \%$ C.I.). The Combined treatment resulted in an antagonistic interaction and showed decreased stress when compared to their respective single stressor treatments (ESM Table S4).

Workers. Individuals from the treatment groups deficient of pollen did not significantly differ from the Newly Emerged workers $(107.6 \pm 12.5 \mathrm{mg}) 14$ days post-treatment initiation (all Ps $>0.585$; ESM Figure S3B). In contrast, individuals from treatment groups that were fed a pollen diet showed a significant increase in body mass post-treatment initiation (all Ps $<0.001$; ESM Figure S3B). Control (135.3 $\pm 15.5 \mathrm{mg}$ ) and Pathogen $(135.8 \pm 14.3 \mathrm{mg})$ revealed the highest increase in body mass $(\sim 26 \%)$ and were significantly heavier than Combined individuals $(107.9 \pm 21.8)$ (all $P s<0.001$; mean \pm S.D.; ESM Figure S3B). The Combined treatment lead to a synergistic interaction and showed increased stress when compared to their respective single stressor treatments (ESM Table S4).

Nosema ceranae spore counts. Drones. No N. ceranae spores were detected in the Newly Emerged individuals; however, spores were detected in both Control ( $0 \pm 0-0$ million) and Malnutrition ( $0 \pm 0-18.8$ million) (median $\pm 95 \%$ C.I.; Fig. 1C). Nevertheless, Control and Malnutrition did not significantly differ from the Newly Emerged treatment group (all $P s>0.885$, median $\pm 95 \%$ C.I.; Fig. 1C). The Pathogen (0.025 $\pm 0-65.3$ million) and Combined ( $0 \pm 0-102$ million) treatment groups showed a significant increase in spores when compared to Controls (all $P s<0.001)$, yet they did not significantly differ from one another $(P=0.592$, median $\pm 95 \%$ C.I., Fig. 1C). The Combined treatment resulted in an antagonistic interaction and decreased stress when compared to their respective single stressor treatments (ESM Table S4).

Workers. N. ceranae spores were not detected in Newly Emerged or Control treatment groups, whereas spores were found in all other treatment groups. Despite $N$. ceranae spore detection, Malnutrition ( $0 \pm 0-9$ million $)$ and Combined $(0 \pm 0.0-41.3$ million) did not significantly differ when compared to Controls $(0 \pm 0-0$ million $)$ (all Ps $>0.113$ ); median \pm C.I.; Fig. 1D). Significantly increased N. ceranae spore counts were detected in the Pathogen treatment $(0.6 \pm 0$ - 81.8 million) when compared to all other treatments (all $P s<0.001)$. This subsequently resulted in an antagonistic interaction and decreased stress for the Combined treatment when compared to their respective single stressor treatments (ESM Table S4). 
A

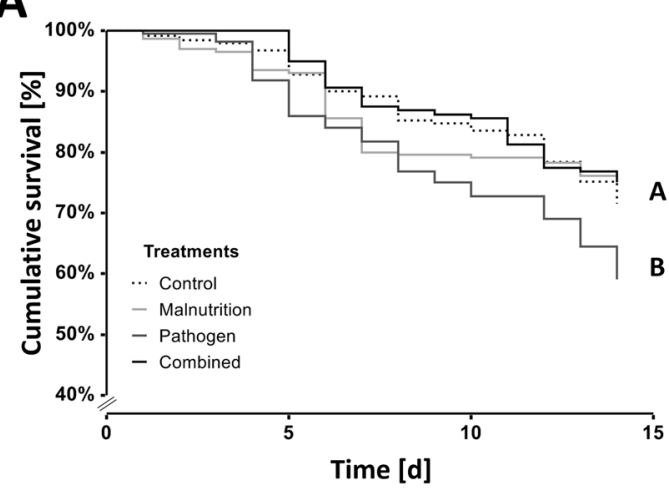

C

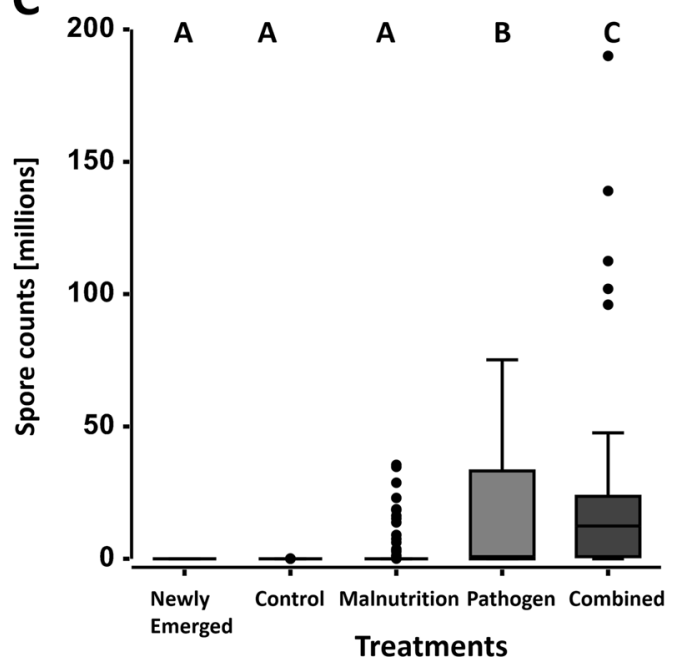

B

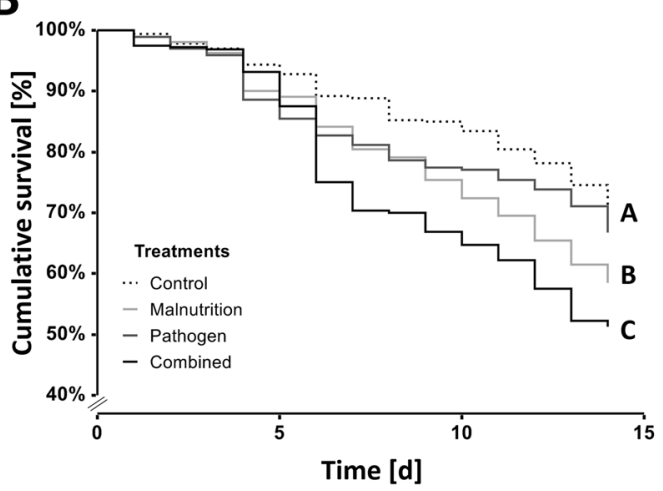

D

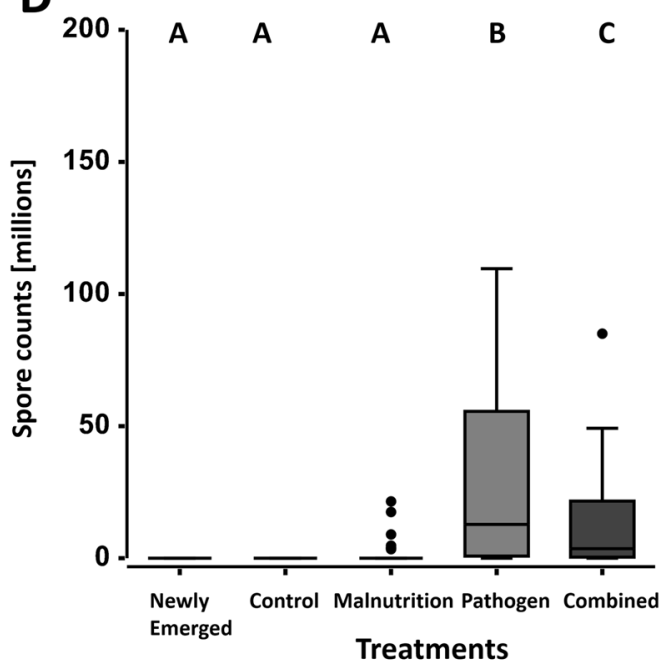

Figure 1. Honeybee drone and worker cage mortality and Nosema ceranae spore loads. (A, B) Survival curves (Kaplan-Meier) indicate the cumulative survival [\%] of honeybees over the 14-day experiment for each treatment. In drones, the Pathogen treatment had significantly lower survival when compared to the remaining treatments. In workers, the Combined treatment had the lowest survival, and the Malnutrition treatment was significantly lower than the Control and Pathogen. Different letters indicate a significant difference between treatments. (C, D) N. ceranae spore loads of individual honeybee drones and workers for each treatment group. For drones, the Pathogen and Combined had significantly higher spore counts than the remaining treatments, but did not differ themselves. For workers, Pathogen had significantly higher spore counts than all other treatments. The boxplots show the inter-quartile range (box), the median (line within box), data range (horizontal lines from box), and outliers (black dots). Different letters indicate a significant difference between treatments.

Comparison between drones and workers. Consumption. Comparisons between the consumption rates of drones and workers were not possible due to the design of the experiment, whereby both were maintained within the same cage.

Survival. Median longevity did not significantly differ between drones and workers for Control or Pathogen treatment groups (both $P s>0.087$; Fig. 2A,C). In sharp contrast, the non-pollen treatments (Malnutrition and Combined) consistently revealed that workers showed significantly reduced survival rates when compared to drones (all $P s<0.001$; Fig. 2B,D), resulting in reduced median longevity by $14.6 \%$ and $24.7 \%$, respectively. Drones from the Pathogen treatment revealed the lowest median longevity, whereas the workers from the Combined treatment revealed the lowest median longevity, subsequently leading to contrasting interaction effects between drones (antagonistic) and workers (synergistic) (ESM Table S4).

Relative body mass. A clear sex difference was observed for body mass 14 days post-treatment initiation. When compared to Newly Emerged individuals, drones revealed significantly reduced body mass (all Ps $<0.001$ ), whereas workers either did not significantly differ or significantly increased. Relative to Controls, body mass loss was greater in workers than in drones for both Malnutrition and Combined treatments, with workers showing increased reductions of $7.27 \%$ and $12.62 \%$, respectively. Additionally, contrasting interaction effects were found between drones (antagonistic) and workers (synergistic) (ESM Table S4). 

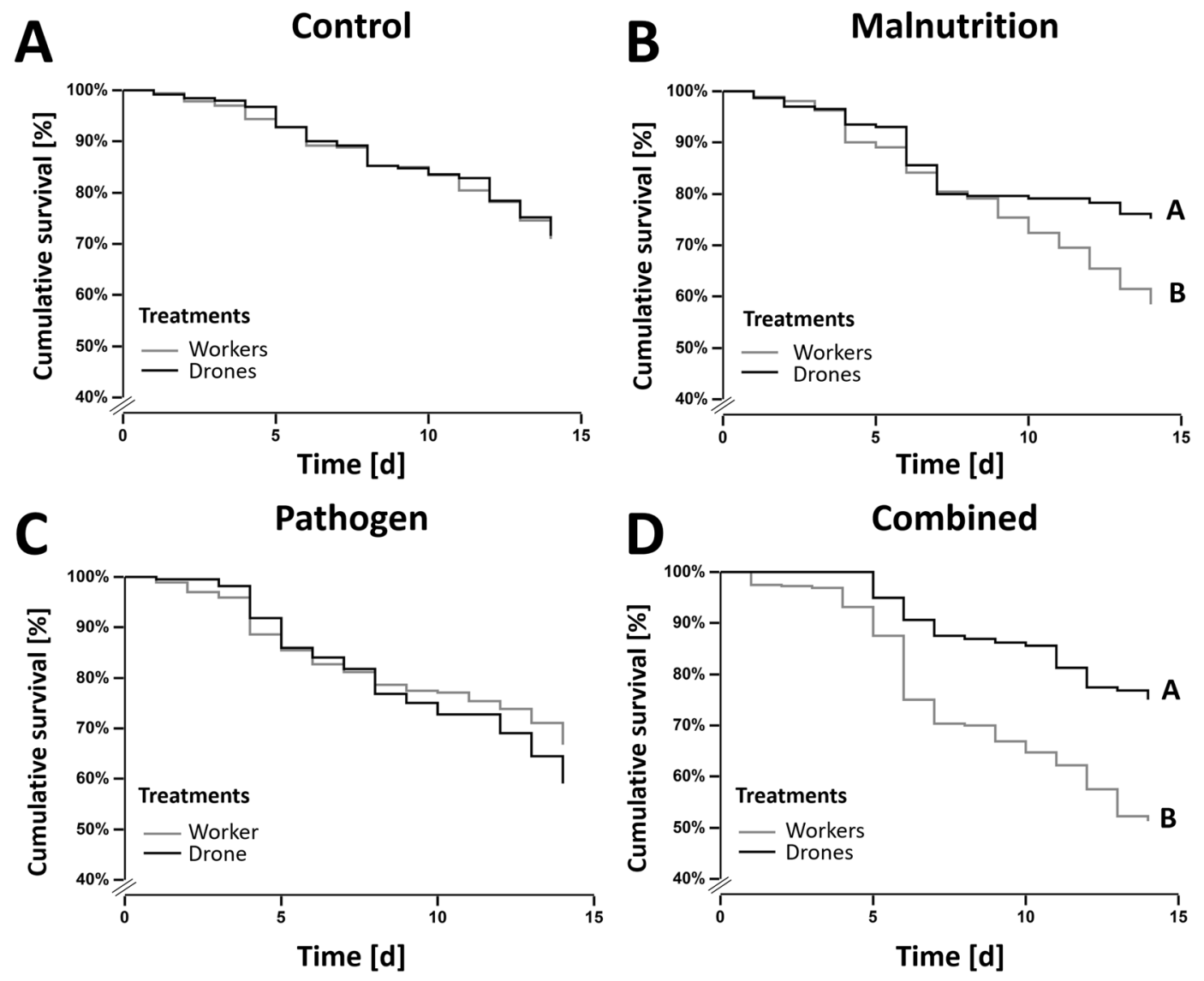

Figure 2. Honeybee drone and worker cage mortality. Survival curves (Kaplan-Meier) compare the cumulative survival [\%] of honeybee (Apis mellifera) workers (grey line) and drones (black line) over the 14-day experiment for each individual treatment: (A) Control, (B) Malnutrition, (C) Pathogen, (D) Combined. The data revealed that workers and drones receiving pollen $(\mathbf{A} \& \mathbf{C})$ did not significantly differ from one another, whereas workers deprived of pollen (B \& D) showed significantly lower survival rates then pollen deprived drones.

Nosema ceranae spore counts. No significant differences in infection rates between drones and workers were found (all Ps $>0.067$ ). Regardless of the treatment group, no significant differences in median spore counts were observed between drones and workers (all $P s>0.166$ ). No significant correlations between body mass and $N$. ceranae were found for drones (Pearson correlation $\left|\mathrm{r}_{342}\right|=-0.038, \mathrm{df}=340, P=0.485$ ) or workers (Pearson correlation $\left.\left|\mathrm{r}_{164}\right|=0.0326, \mathrm{df}=162, P=0.687\right)$. Both drones and workers revealed the same interaction effects (antagonistic and reduced stress; ESM Table S4). No significant difference in infection efficiency was observed between workers and drones for all treatment groups (all $P s>0.067)$. Likewise, no difference in infection efficiency was observed when comparing Pathogen to Combined $\left(\chi^{2}=2.45, \mathrm{DF}=1, P=0.118\right)$.

\section{Discussion}

Our data show distinct stressor interactions within a single species. While diploid female honeybee workers exposed to both malnutrition and the pathogen N. ceranae showed synergistic interactions and increased stress, haploid male drones showed antagonistic interactions and decreased stress. Division of labour in the social insects apparently overrides any possible disadvantage of hemizygosity as predicted by the haploid-susceptibility hypothesis. Our study emphasizes the urgent need to empirically test the actual nature of stressor interactions across a range of susceptibility factors within a model system.

Our findings must be interpreted within the context of laboratory conditions and definite methodological differences to other studies (i.e. bulk vs. hand feeding, varied spore solutions). Indeed, our cage set-up greatly improved drone survival under laboratory conditions, which is historically $l_{0} w^{38,39}$. By limiting the extreme stress of cages on drones, we achieved the same survival rates in drones and workers in the Controls, allowing for a direct comparison of treatment effects between the honeybee sexes. Since the pollen was not irradiated, this explains the N. ceranae infections in the Controls ${ }^{37,40}$. Nevertheless, spore counts did not significantly differ amongst non-pathogen-exposed groups, including the newly emerged individuals, subsequently having no significant effect. We found no significant differences in sucrose consumption between treatments, which is in line with previous studies ${ }^{40,41}$. Since other studies found effects ${ }^{37,42,43}$, it is evident that infection with $N$. ceranae does not necessarily lead to increased hunger levels. Our data also show no difference amongst treatments for pollen consumption ${ }^{37,44}$. However, pollen consumption was highest during the first week when newly emerged bees utilize protein for organ and tissue development ${ }^{40,45}$. Indeed, the Malnutrition treatment reduced body mass in 
both drones (9\%) and workers (16\%) compared to their relative Controls (as in ${ }^{37}$ ), which may have an impact on bee performance ${ }^{46}$.

While malnutrition alone caused significant worker mortality (18\%), in line with previous studies ${ }^{37,40,47}$, this was not the case in drones. Since workers have higher pollen requirements compared to drones ${ }^{48}$ due to division of labour (e.g. jelly production ${ }^{49}$ ), it appears evident that lack of protein will cause more stress in the workers. Furthermore, feeding other bees is costly and can reduce worker lifespan ${ }^{50}$. Therefore, the attending nurse bees in our experiment were per se more active than the drones, who in sharp contrast received attendance.

No difference in infection rates, spore loads or survival were found between the Pathogen treatment drones and workers. Nevertheless, our data confirm that $N$. ceranae infected workers (Pathogen treatment) display higher spore loads when pollen-fed ${ }^{37,43}$. The addition of pollen, however, did not impact drone spore load, again possibly due to their more limited intake of pollen ${ }^{49}$. However, drones from the Pathogen treatment had a lower survival compared to their Control and Combined treatments, which was not the case for workers. Since spore loads did not differ between Combined and Pathogen treatments in drones, this suggests that higher mortality in the Pathogen treatment is not induced by N. ceranae itself. Alternatively, starvation due to less efficient attending of highly infected workers in the Pathogen treatment may explain this phenomenon ${ }^{43}$.

The data from the Combined treatments were most remarkable. In sharp contrast to our predictions based on the published literature, stressor interactions were antagonistic in drones and synergistic in workers. Therefore, the data do not support the haploid-susceptibility hypothesis ${ }^{51,52}$, predicting that effects should be amplified in the haploid drones. Indeed, drones showed antagonistic effects and decreased stress, wherein the Combined treatment survival, surprisingly, did not differ from the Controls. On the other hand, worker exposure to combined stressors revealed synergistic effects and increased stress. A significantly reduced worker survival and relative body mass was found compared to both Controls and drones from their respective treatment. Since the Combined exposed workers revealed the lowest survival of all groups, yet had fewer spores than the Pathogen treatment (confirming ${ }^{37}$ ), this clearly shows the synergistic and increased stress effect. This highlights the importance of adequate protein nutrition for worker tolerance to pathogen infections ${ }^{53}$ and attending nest mates ${ }^{48}$. Indeed, workers are actually exposed to three and not only two stressors. Besides lack of protein and the pathogen, workers are confronted with social stress imposed by male nest mates actively seeking attention, especially within the first few days of emergence ${ }^{54}$. It therefore appears evident that the stressor interactions are different between the sexes. In general, nomen est omen, hence workers are performing all tasks to maintain a functional colony due to division of labour in the social insects ${ }^{27}$. Therefore, life-history differences between drones and workers may outweigh the potential negative effect of hemizygoisity at loci towards these stressors. Workers are usually short-lived, replaceable units that do not normally reproduce ${ }^{27}$. On the other hand, drones are sexuals and their survival is essential for reproduction and colony fitness ${ }^{55}$. Therefore, superorganism resilience, the ability to tolerate the loss of somatic cells (=workers) as long as the germline (=reproduction) is maintained ${ }^{56}$, may ultimately explain why drones are actually performing better than workers. Workers can be replaced easily and a high turnover rate may even be adaptive at the colony level, e.g. not enabling ample pathogen reproduction ${ }^{56,57}$.

Division of labour in the social insects is just one factor driving susceptibility to stressor interactions in a species. Other drivers are likely to be ontogenetic ${ }^{58}$, senescence ${ }^{59}$, sex and polymorphism (e.g. winter vs summer honey bees ${ }^{60}$ ). In this particular case, the workers were the weakest link. It is apparent that this may be very different in other cases (e.g. in case of drones and pesticides ${ }^{61}$ ). Therefore, we suggest an a priori screening of the model system for the chances of the susceptibility factors to occur and the actual impact they have at individual and population level. In light of the documented importance of stressor interactions ${ }^{11-13}$, it appears prudent to take those points into account to ensure efficient nature conservation efforts and sustainable food security.

\section{Conclusion}

Our study provides clear evidence for extreme differences in stressor interactions within a single species, ranging from antagonism to synergism. It, therefore, appears inevitable to consider a range of factors known to govern the susceptibility towards stressor interactions such as ontogenetic, senescence, sexes and division of labour in the social insects, as shown here. Most importantly, multiple stressor interactions cannot be regarded as synergistic per se, but need to be empirically tested across a range of possible susceptibility factors.

\section{Material and methods}

Experimental design. The experiment was conducted in June and July 2018 at the Institute of Bee Health, University of Bern, Switzerland, using seven local, non-related and queenright A. mellifera colonies and Best Management Practices, incl. an oxalic (2.7\%) acid Varroa destructor treatment in the previous winter and early-spring ${ }^{62}$.

Source of drones and workers. To obtain sufficient drones and workers of a known age, all queens were caged in their colonies for 48 hours on frames with organic drone and worker wax foundations. Brood frames were transferred 24 hours prior to adult emergence to a laboratory incubator maintained at $34.5^{\circ} \mathrm{C}$ and $60 \% \mathrm{RH}$ in darkness ${ }^{63}$. To foster drone emergence and feeding, $\sim 50$ adult worker from each colony were added to their respective drone frame ${ }^{64}$. Post-emergence, drones and workers without clinical symptoms of disease ${ }^{65-67}$ were randomly placed in standard hoarding cages $\left[250 \mathrm{~cm}^{3}\right]^{68}$.

Nosema ceranae cultivation and inoculation. Spore solutions were freshly obtained using routine protocols, including tests with species-specific PCR primers ${ }^{69}$. Five N. ceranae positive foragers (all 20 negative for Nosema apis (ESM Figure S1 and Table S1) were used to infect newly emerged, caged workers via bulk feeding ${ }^{70}$ to obtain spore solutions of known concentrations ${ }^{35,71}$. 
Treatments. To investigate sub-lethal and lethal effects of malnutrition and N. ceranae infections, singly and in combination, on drones and workers, a fully-crossed hoarding cage experiment was designed using the following four feeding treatment groups: 1 . Sucrose solution and pollen (=Controls), 2 . Sucrose solution only (=Malnutrition), 3. Sucrose solution, pollen, plus $\sim 10,000$ N. ceranae spores/bee (=Pathogen) and, 4. Sucrose solution only, plus $\sim 10,000 \mathrm{~N}$. ceranae spores/bee (=Combined) (ESM Table S2). All bees were starved for two hours ${ }^{37,72}$ before solutions were provided via bulk feeding ${ }^{70}$. Optimal nutritional conditions were provided to Control and Pathogen treatment groups by enabling access to both a carbohydrate (sucrose solution) and protein source (corbicular pollen) ${ }^{36}$. In contrast, the Malnutrition and Combined treatment groups lacked a protein source, thereby imitating nutritional stress. The provided corbicular pollen was not gamma-ray irradiated. Bulk feeding of $N$. ceranae occurred only within the first 24 hours of the experiment. Once the spore suspension had been consumed, it was replaced with a pathogen-free $50 \%[\mathrm{w} / \mathrm{w}]$ sucrose solution in all cases.

Hoarding cages. In total, 96 hoarding cages (22-26 per treatment group) were each filled with 10 drones and 20 workers $^{68}$ (ESM Table S2), randomly assigned to a treatment group and were maintained in complete darkness at $30{ }^{\circ} \mathrm{C}$ and $60 \% \mathrm{RH}^{63}$. All cages contained a $5 \mathrm{ml}$ syringe providing $50 \%$ [w/v] sucrose solution ad libitum to provide sufficient carbohydrates. Depending on the treatment group, hoarding cages contained an additional $2.5 \mathrm{ml}$ Eppendorf feeder providing ad libitum pollen paste (70\% fresh corbicular pollen, $30 \%$ powder sugar) as a protein source $^{36}$.

Food consumption and mortality. Sucrose solution and pollen paste consumption were weighed every other day to test for differences in nutritional demand ${ }^{42}$. The sugar water syringes were replaced after being weighed to avoid potential mold formation ${ }^{63}$. Since the average weight loss of sucrose solution from the syringes due to evaporation $(<1 \%)$ was negligible (three empty cages kept in the incubator), this factor was excluded. The daily sugar consumption per bee $[\mathrm{mg}]$ was calculated by correcting for the number of individuals alive per cage over the 48 -hour time period ${ }^{73}$. We tested the sugar consumption in 12 random cages per treatment group $(\mathrm{N}=48)$ at six time points throughout the experiment $(\mathrm{N}=271)$. Pollen consumption was calculated in the same way, however, only the treatments fed with pollen were used $(\mathrm{N}=24$ cages, 137 measurements). Mortality was recorded daily, whereby dead bees were counted and removed. Cages with non-functional feeders $(\mathrm{N}=10)$ were excluded. Both consumption and survival were monitored until the experiment was terminated 14 days post-treatment initiation ${ }^{39,70,74}$. In total, we monitored the survival of 2,880 bees.

Bee body mass and Nosema ceranae spore counts. Teneral body mass (drones: $\mathrm{N}=238$, workers: $\mathrm{N}=240$ ) and $N$. ceranae spore counts (drones and workers: $\mathrm{N}=80$ each) were determined for individual drones and workers upon emergence and 14 days post-treatment (drones: $\mathrm{N}=360$, workers: $\mathrm{N}=210)^{35}$.

Statistical analyses. All tests and figures were performed using NCSS $2019^{75}$. Data were tested for normality using the Shapiro-Wilk's test and visually inspected using Q-Q-plots ${ }^{76}$. While body mass and sucrose consumption were normally distributed (Shapiro-Wilk's test, $P>0.05$, ESM Table S3) and analysed using a One-way ANOVA, pollen consumption per bee and N. ceranae spore counts were non-normally distributed (Shapiro- Wilk's test, $P<0.05$, ESM Table S3) and analysed using a Kruskal-Wallis One-way ANOVA ${ }^{76}$. Post-hoc comparisons of all variables were conducted by using a multiple pairwise comparisons test (Bonferroni Multiple Comparison Test (bmct)). Additionally, pollen consumption per bee over time was evaluated using repeated measures ANOVA (Mauchly's Test for Sphericity was not significant $(P>1.00)$ ). Survival analyses were performed using Kaplan-Meier cumulative survival curves and Log-Rank values were calculated to determine differences amongst treatment groups. An XY scatter plot and the Pearson's correlation coefficient was used to assess for a potential correlation between body mass and $N$. ceranae spore counts. Additionally, $\chi^{2}$-tests were used to compare infection rates between treatments and between drones and workers.

Interactions. To investigate interaction effects between malnutrition and N. ceranae we employed an additive effects model ${ }^{77,78}$. In the additive model, synergism or antagonism occur when the combined effect of multiple stressors is greater (synergism) or less (antagonism) than the sum of effects elicited by individual stressors ${ }^{79}$. Additionally, to gain clarification on the degree of stress, the simple comparative model was also applied ${ }^{77}$. This model states that increased or decreased stress occurs when the combined effect of multiple stressors is greater (increased) or less (decreased) than the effect of the single worst stressor. Interactive stress effects on consumption, body mass and survival were calculated as the percent differences in treatments relative to controls, whereby the mean body mass [mg], median cumulative survival [\%] and median N. ceranae spore counts [spores bee ${ }^{-1}$ millions] at day 14 were used for the calculations (ESM Table S4).

\section{Data availability}

The complete raw data can be found at the Dryad repository. https://doi.org/10.5061/dryad.v9s4mw6r7

Received: 8 January 2020; Accepted: 21 February 2020;

Published online: 13 March 2020

\section{References}

1. Hughes, J. B., Daily, G. C. \& Ehrlich, P. R. Population diversity: Its extent and extinction. Science 278, 689-692 (1997).

2. Sala, O. E. et al. Global biodiversity scenarios for the year 2100 . Science $\mathbf{2 8 7}, 1770-1774$ (2000).

3. Barnosky, A. D. et al. Has the Earth's sixth mass extinction already arrived? Nature 471, 51-57 (2011).

4. Ceballos, G., Ehrlich, P. R. \& Dirzo, R. Biological annihilation via the ongoing sixth mass extinction signalled by vertebrate population losses and declines. Proc. Natl. Acad. Sci. 114, E6089-E6096 (2017).

5. Régnier, C. et al. Mass extinction in poorly known taxa. Proc. Natl. Acad. Sci. 112, 7761-7766 (2015). 
6. Klein, A.-M. et al. Importance of pollinators in changing landscapes for world crops. Proc. Biol. Sci. 274, 303-13 (2007).

7. Garibaldi, La et al. Wild pollinators enhance fruit set of crops regardless of honey bee abundance. Science 339, 1608-11 (2013).

8. Dirzo, R. et al. Defaunation in the Anthropocene. Science 345, 401-406 (2014).

9. Powney, G. D. et al. Widespread losses of pollinating insects in Britain. Nat. Commun. 10, 1-6 (2019).

10. Seibold, S. et al. Arthropod decline in grasslands and forests is associated with drivers at landscape level. Nature 574, 1-34. (2019).

11. Franco, A. M. A. et al. Impacts of climate warming and habitat loss on extinctions at species' low-latitude range boundaries. Glob. Chang. Biol. 12, 1545-1553 (2006).

12. Pounds, J. A. et al. Widespread amphibian extinctions from epidemic disease driven by global warming. Nature 439, 161-167 (2006).

13. Gossner, M. M. et al. Land-use intensification causes multitrophic homogenization of grassland communities. Nature 540(7632), 266 (2016).

14. Potts, S. G. et al. Global pollinator declines: trends, impacts and drivers. Trends Ecol. Evol. 25, 345-53 (2010).

15. Didham, R. K., Tylianakis, J. M., Gemmell, N. J., Rand, T. A. \& Ewers, R. M. Interactive effects of habitat modification and species invasion on native species decline. Trends Ecol. Evol. 22, 489-496 (2007).

16. Cameron, S. A. et al. Patterns of widespread decline in North American bumble bees. Proc. Natl. Acad. Sci. 108, 662-667 (2011).

17. Baude, M. et al. Historical nectar assessment reveals the fall and rise of floral resources in Britain. Nature 530, 85-88 (2016).

18. Miyo, T., Akai, S. \& Oguma, Y. Seasonal fluctuation in susceptibility to insecticides within natural populations of Drosophila melanogaster. Empirical observations of fitness costs of insecticide resistance. Genes Genet. Syst. 75, 97-104 (2000).

19. Baron, G. L., Raine, N. E. \& Brown, M. J. F. General and species-specific impacts of a neonicotinoid insecticide on the ovary development and feeding of wild bumblebee queens. Proc. R. Soc. B Biol. Sci. 284, 20170123 (2017).

20. Ranjeva, S. et al. Age-specific differences in the dynamics of protective immunity to influenza. Nat. Commun. 10, 1-11 (2019).

21. Fransen, J. J., Winkelman, K. \& van Lenteren, J. C. The differential mortality at various life stages of the greenhouse whitefly, Trialeurodes vaporariorum (Homoptera: Aleyrodidae), by infection with the fungus Aschersonia aleyrodis (Deuteromycotina: Coelomycetes). J. Invertebr. Pathol. 50, 158-165 (1987).

22. Sheridan, L. A. D., Poulin, R., Ward, D. F. \& Zuk, M. Sex differences in parasitic infections among arthropod hosts: Is there a male bias? Oikos 88, 327-334 (2000).

23. Úbeda, F. \& Jansen, V. A. A. The evolution of sex-specific virulence in infectious diseases. Nat. Commun. 7, 1-9 (2016).

24. Semlitsch, R. D., Bridges, C. M. \& Welch, A. M. Genetic variation and a fitness tradeoff in the tolerance of gray treefrog (Hyla versicolor) tadpoles to the insecticide carbaryl. Oecologia 125, 179-185 (2000).

25. Evans, J. D., Shearman, D. C. A. \& Oldroyd, B. P. Molecular basis of sex determination in haplodiploids. Trends Ecol. Evol. 19, 1-3 (2004).

26. O'Donnell, S. \& Beshers, S. N. The role of male disease susceptibility in the evolution of haplodiploid insect societies. Proc. Biol. Sci. 271, 979-83 (2004).

27. Wilson, E.O. The Insect Societies. Harvard University Belknap Press, Cambridge, MA (1971).

28. Schmid-Hempel, P. Parasites in social insects. Princeton University Press, Princeton, New Jersey (1998).

29. Rosengaus, R. B. \& Traniello, J. F. A. Disease susceptibility and the adaptive nature of colony demography in the dampwood termite Zootermopsis angusticollis. Behav. Ecol. Sociobiol. 50, 546-556 (2001).

30. Calderone, N. W. Insect pollinated crops, insect pollinators and US agriculture: trend analysis of aggregate data for the period 1992-2009. PLoS One 7, e37235 (2012).

31. EFSA. EFSA Guidance Document on the risk assessment of plant protection products on bees (Apis mellifera, Bombus spp. and solitary bees). EFSA J. 11, 268 (2014).

32. Beye, M., Hasselmann, M., Fondrik, M. K., Page, R. E. Jr. \& Omholt, S. W. The gene csd is the primary signal for sexual development in the honeybee and encodes an SR-type protein. Cell 114, 419-429 (2003).

33. Antúnez, K. et al. Immune suppression in the honey bee (Apis mellifera) following infection by Nosema ceranae (Microsporidia). Environ. Microbiol. 11, 2284-90 (2009).

34. Alaux, C., Ducloz, F., Crauser, D. \& Le Conte, Y. Diet effects on honeybee immunocompetence. Biol. Lett. 6, 1-4 (2010).

35. Hornitzky, M. Nosema Disease - Literature review and three year survey of beekeepers - Part 2. RIRDC Publ., 35 (2008)

36. Brodschneider, R. \& Crailsheim, K. Nutrition and health in honey bees. Apidologie 41, 278-294 (2010).

37. Tritschler, M. et al. Protein nutrition governs within-host race of honey bee pathogens. Sci. Rep., 1-11 (2017).

38. Adam, R., Adriana, M. \& Ewa, P. An influence of chosen feed additives on the life-span of laboratory held drones and the possibility of semen collection. J. Apic. Sci. 54, 25-36 (2010).

39. Retschnig, G. et al. Sex-specific differences in pathogen susceptibility in honey bees (Apis mellifera). PLoS One 9, e85261 (2014b).

40. Jack, C. J., Uppala, S. S., Lucas, H. M. \& Sagili, R. R. Effects of pollen dilution on infection of Nosema ceranae in honey bees. J. Insect Physiol. 87, 12-19 (2016).

41. Aufauvre, J. et al. Parasite-insecticide interactions: a case study of Nosema ceranae and fipronil synergy on honeybee. Sci. Rep. 2, 326 (2012).

42. Mayack, C. \& Naug, D. Energetic stress in the honeybee Apis mellifera from Nosema ceranae infection. J. Invertebr. Pathol. 100, 185-8 (2009).

43. Naug, D. \& Gibbs, A. Behavioral changes mediated by hunger in honeybees infected with Nosema ceranae. Apidologie 40, 595-599 (2009).

44. Basualdo, M., Barragán, S. \& Antúnez, K. Bee bread increases honeybee haemolymph protein and promote better survival despite of causing higher Nosema ceranae abundance in honeybees. Environ. Microbiol. Rep. 6, 396-400 (2014).

45. Crailsheim, K. et al. Pollen consumption and utilization in worker honeybees (Apis mellifera carnica): Dependence on individual age and function. J. Insect Physiol. 38, 409-419 (1992).

46. Heinrich, B. Thermoregulation in endothermic insects. Science. 185(4153), 747-756 (1974).

47. Zheng, H.-Q. et al. Spore loads may not be used alone as a direct indicator of the severity of Nosema ceranae infection in honey bees Apis mellifera (Hymenoptera:Apidae). J. Econ. Entomol. 107, 2037-2044 (2014).

48. Hrassnigg, N. \& Crailsheim, K. Differences in drone and worker physiology in honeybees (Apis mellifera) 1. Apidologie 36, 255-277 (2005).

49. Szolderits, M. J. \& Crailsheim, K. A comparison of pollen consumption and digestion in honeybee (Apis mellifera carnica) drones and workers. J. Insect Physiol. 39, 877-881 (1993).

50. Eyer, M., Dainat, B., Neumann, P. \& Dietemann, V. Social regulation of ageing by young workers in the honey bee, Apis mellifera. Exp. Gerontol. 87, 84-91 (2017).

51. Ruiz-González, M. X. \& Brown, M. J. F. Males vs workers: Testing the assumptions of the haploid susceptibility hypothesis in bumblebees. Behav. Ecol. Sociobiol. 60, 501-509 (2006).

52. Cappa, F., Beani, L., Cervo, R., Grozinger, C. \& Manfredini, F. Testing male immunocompetence in two hymenopterans with different levels of social organization: "live hard, die young? Biol. J. Linn. Soc. 114, 274-278 (2015).

53. Miller, C. V. \& Cotter, S. C. Pathogen and immune dynamics during maturation are explained by Bateman's Principle. Ecological entomology 42, 28-38 (2017).

54. Free, J. B. The food of adult drone honeybees (Apis mellifera). Br. J. Anim. Behav. 5, 7-11 (1957).

55. Kraus, F. B., Neumann, P., Scharpenberg, H., Van Praagh, J. \& Moritz, R. F. A. Male fitness of honeybee colonies (Apis mellifera L.). J. Evol. Biol. 16, 914-920 (2003). 
56. Straub, L., Williams, G. R. G. R., Pettis, J., Fries, I. \& Neumann, P. Superorganism resilience: Eusociality and susceptibility of ecosystem service providing insects to stressors. Curr. Opin. Insect Sci. 12, 109-112 (2015).

57. Seeley, T. D. Life history strategy of the honey bee, Apis mellifera. Oecologia 32(1), 109-118 (1978).

58. Wilson-Rich, N., Dres, S. T. \& Starks, P. T. The ontogeny of immunity: development of innate immune strength in the honey bee (Apis mellifera). Journal of insect physiology 54(10-11), 1392-1399 (2008).

59. Doums, C., Moret, Y., Benelli, E. \& Schmid-Hempel, P. Senescence of immune defence in Bombus workers. Ecological Entomology 27(2), 138-144 (2002).

60. Steinmann, N., Corona, M., Neumann, P. \& Dainat, B. Overwintering is associated with reduced expression of immune genes and higher susceptibility to virus infection in honey bees. PloS one 10(6), e0129956 (2015).

61. Friedli, A., Williams, G. R., Bruckner, S., Neumann, P. \& Straub, L. The weakest link: Haploid honey bees are more susceptible to neonicotinoid insecticides. Chemosphere 242, 125145 (2019).

62. Rosenkranz, P., Aumeier, P. \& Ziegelmann, B. Biology and control of Varroa destructor. J. Invertebr. Pathol. 103, 96-119 (2010).

63. Williams, G. R. et al. Standard methods for maintaining adult Apis mellifera in cages under in vitro laboratory conditions. J. Apic. Res. 52, 1-36 (2013).

64. Currie, R. W. The biology and behaviour of drones. Bee World 68, 129-143 (1987).

65. Williams, G. R. et al. Deformed wing virus in western honey bees (Apis mellifera) from Atlantic Canada and the first description of an overtly-infected emerging queen. J. Invertebr. Pathol. 101, 77-9 (2009).

66. Dainat, B. \& Neumann, P. Clinical signs of deformed wing virus infection are predictive markers for honey bee colony losses. J. Invertebr. Pathol. 112, 278-80 (2013).

67. Dietemann, V. et al. Standard methods for Varroa research. J. Apic. Res. 52, 1-54 (2013).

68. Straub, L. et al. Neonicotinoid insecticides can serve as inadvertent insect contraceptives. R. Soc. Proc. B 283, 20160506 (2016).

69. Chen, Y., Evans, J. D., Smith, I. B. \& Pettis, J. S. Nosema ceranae is a long-present and wide-spread microsporidian infection of the European honey bee (Apis mellifera) in the United States. J. Invertebr. Pathol. 97, 186-188 (2008).

70. Fries, I. et al. Standard methods for Nosema research. J. Apic. Res. 52, 1-28 (2013).

71. Cantwell, G. E. Standard methods for counting Nosema spores. Am. Bee J. 110, 222-223 (1970).

72. Retschnig, G., Neumann, P. \& Williams, G. R. Thiacloprid-Nosema ceranae interactions in honey bees: host survivorship but not parasite reproduction is dependent on pesticide dose. J. Invertebr. Pathol. 118, 18-9 (2014a).

73. Tosi, S. \& Nieh, J. C. A common neonicotinoid pesticide, thiamethoxam, alters honey bee activity, motor functions, and movement to light. Sci. Rep. 7, 1-13 (2017).

74. Paxton, R. J., Klee, J., Korpela, S. \& Fries, I. Nosema ceranae has infected Apis mellifera in Europe since at least 1998 and may be more virulent than Nosema apis. Apidologie 38, 558-565 (2007).

75. NCSS 2019 Statistical Software. NCSS, LLC. Kaysville, Utah, USA, ncss.com/software/ncss (2019).

76. Pirk, C. W. W. et al. Statistical guidelines for Apis mellifera research. J. Apic. Res. 52, 1-24 (2013).

77. Folt, C. L., Chen, C. Y., Moore, M. V. \& Burnaford, J. Synergism and antagonism among multiple stressors. Limmol. Ocean. 44, 864-877 (1999).

78. Straub, L. et al. Neonicotinoids and ectoparasitic mites synergistically impact honeybees. Sci. Rep. 9, 8159 (2019).

79. Hay, M. E. Defensive synergisms? Reply to Pennings. Ecology 77, 1950-1952 (1996).

\section{Acknowledgements}

Maria a Marca and Christoph Moor from the BAFU engaged us in fruitful discussions about the topic of bees and multiple stressors. Financial support was provided by the Bundesamt für Umwelt (BAFU) (16.0091.PJ/R1021664) to L.S., A.M. and P.N., by Agroscope to L.S. and P.N., by the Vinetum Foundation to P.N.

\section{Author contributions}

L.S., A.M., and P.N. designed the experiment and wrote the manuscript; L.S., A.M., V.S., A.J.W.M.M., A.F., I.K., E.K. collected laboratory data; O.V.Y. performed molecular laboratory analyses; P.N. provided materials; L.S. and A.M. designed the statistical analysis; L.S., A.M., V.S., and P.N. analysed the data. All authors edited and approved the manuscript.

\section{Competing interests}

The authors declare no competing interests.

\section{Additional information}

Supplementary information is available for this paper at https://doi.org/10.1038/s41598-020-61371-x.

Correspondence and requests for materials should be addressed to L.S. or A.M.

Reprints and permissions information is available at www.nature.com/reprints.

Publisher's note Springer Nature remains neutral with regard to jurisdictional claims in published maps and institutional affiliations.

Open Access This article is licensed under a Creative Commons Attribution 4.0 International License, which permits use, sharing, adaptation, distribution and reproduction in any medium or format, as long as you give appropriate credit to the original author(s) and the source, provide a link to the Creative Commons license, and indicate if changes were made. The images or other third party material in this article are included in the article's Creative Commons license, unless indicated otherwise in a credit line to the material. If material is not included in the article's Creative Commons license and your intended use is not permitted by statutory regulation or exceeds the permitted use, you will need to obtain permission directly from the copyright holder. To view a copy of this license, visit http://creativecommons.org/licenses/by/4.0/.

(c) The Author(s) 2020 